\section{Review of Three Pediatric Wheat-Related Disorder Cases with Disparate Clinical Manifestations}

\author{
Tom O'Bryan ${ }^{1,2,3 *}$ \\ ${ }^{1}$ Adjunct Faculty, The Institute for Functional Medicine, Gig Harbor, WA, \\ USA \\ ${ }^{2}$ Adjunct Faculty, The National University of Life Sciences, Lombard, IL, \\ USA \\ ${ }^{3}$ Adjunct Faculty, Integrative and Functional Nutrition Academy, Tampa, \\ $F L$, USA
}

\begin{abstract}
The consumption of wheat-based products is high in most Western countries (e.g. Europe, United States) and is increasing in Eastern countries as a consequence of a shift toward a Western lifestyle. Historically, Wheat-Related Disorders (WRD) referred only to wheat allergy and celiac disease. In recent years, a growing number of subjects worldwide have reported intestinal and extraintestinal symptoms, without the diagnostic features of celiac disease or wheat allergy. In these subjects, symptoms of a wheat-related disorder may originate from non-celiac gluten sensitivity, the non-gluten antibody target protein serpins, purinins, $\alpha$-amylase/protease inhibitors, globulins, farinins, wheat exorphin sensitivity, wheat germ agglutinin sensitivity, wheat amylase-trypsin inhibitor sensitivity, and/or FODMAP (fermentable oligo-, di-, mono- saccharides and polyols) sensitivity. This article reviews the pertinent literature and presents three pediatric cases of wheat-related disorders that present with varied clinical presentations: liver failure, type 1 diabetes mellitus and a conjunctival tumor believed to be Kaposi's sarcoma. All conditions responded rapidly to a wheat-free diet. A wheat-related disorder (with or without
\end{abstract}

*Corresponding author: Tom O'Bryan, 315 South Coast Highway 101 Suite U539, Encinitas, California 92024, USA, Tel: +1 877458 7656; E-mail: Tob1152@gmail.com

Citation: O'Bryan T (2018) Review of Three Pediatric Wheat-Related Disorder Cases with Disparate Clinical Manifestations. J Gastroenterol Hepatology Res 3: 020.

Received: March 19, 2018; Accepted: August 03, 2018; Published: August 20, 2018

Copyright: (c) 2018 O'Bryan T. This is an open-access article distributed under the terms of the Creative Commons Attribution License, which permits unrestricted use, distribution, and reproduction in any medium, provided the original author and source are credited. celiac disease) may affect any organ or system including cardiovascular disease, neurological diseases, connective tissue diseases, allergies, inflammatory bowel disease, nephritis and others. While there is increasing awareness that wheat-related disorders can manifest with extraintestinal symptoms, clinicians still rely too heavily on the presence of gastrointestinal symptoms to suspect a wheat-related disorder. These three cases showed wheat-related pathogenesis affecting diverse organs, such as the liver, pancreas, or eye, without marked gastrointestinal symptoms. Therefore, in patients with unexplained symptoms, who do not improve with standard therapies, it may be prudent to screen for serological indicators of a WRD. Clinical awareness of the diversity of presentations of a WRD may lead to earlier suspicion, investigation and a reduction in co-morbidities.

Keyword: Adverse reactions to foods; Celiac disease; Conjunctival tumor; Kaposi's sarcoma; Liver failure; Non-celiac gluten sensitivity; Type 1 diabetes mellitus; Wheat-related disorders

\section{Introduction}

In industrialized nations such as the United States, the United Kingdom, and Germany, approximately $20 \%$ of the population has been reported to experience Adverse Reactions to Food (ARF) with wheat, nuts, fruits, and milk among the most common triggers [1]. Most ARF are not mediated by the immune system, such as lactose intolerance which is the most common ARF worldwide [1]. ARF may result in both gastrointestinal symptoms and/or extra-intestinal symptoms. Gastrointestinal food allergies (an IgE immune response) do exist in both children and adults but the majority of symptoms from $\mathrm{ARF}$ are due to non-immunologic reactions to foods [1]. Thus, although immunoglobulin testing of antibodies to food proteins (IgE, $\operatorname{IgG}, \operatorname{IgA}, \operatorname{IgM})$ is of clinical value in identifying an adverse reaction, exclusive use of such testing may be limiting.

Historically, the primary Wheat-Related Disorders (WRDs) have been identified as celiac disease (affecting approximately 1 in 100 in the general population) and wheat allergy (affecting approximately 1 in 1000 in the general population) [2]. After celiac disease and wheat allergy have been (largely) excluded, numerous Non-Celiac Wheat Sensitivity (NCWS) disorders may be considered. Recent studies and experimental data strongly indicate that NCWS exists in a substantial proportion of the population, that it is an innate immune reaction to wheat and that patients often present with extra-intestinal symptoms, such as worsening of an underlying inflammatory disease in clear association with wheat consumption [3].

A category of sensitivities referred to as non-celiac wheat sensitivity may include:

- Non-Celiac Gluten Sensitivity (NCGS), whose published prevalence varies widely $(0.5-13 \%)$ in western populations $[4,5]$

- Wheat germ agglutinin sensitivity (a carbohydrate-binding protein that also functions as a natural pesticide) which has been associated with inhibition of gut epithelial cell repair and stimulating synthesis of pro-inflammatory cytokines and may have an antigenic 
impact on the intestinal epithelium at nano-molar concentrations $[6,7]$

- Wheat Amylase Trypsin Inhibitors (ATI) which stimulate an innate immune response via activation of TLR4 on monocytes, macrophages and dendritic cells, leading to release of proinflammatory cytokines within 2-12 h [8]. Wheat ATIs are a family of up to 17 similar proteins of molecular weights around $15 \mathrm{kD}$ and represent $2-4 \%$ of the wheat protein. With oral ingestion, they co-stimulate antigen presenting cells and promote $\mathrm{T}$ cell activation in celiac disease, but also in other immune-mediated diseases within and outside the GI tract [3]

- FODMAPs (Fermentable Oligo-, Di-, Mono-saccharides and Polyols) which may primarily cause gastrointestinal symptoms through gaseous production and osmotic diarrhea and are present in many food products, with fructans (arabinoxylans) commonly present in wheat [9-12]

- Exorphin sensitivity (the opiate receptor agonists gluteomorphins and prodynorphins in wheat) [13]

If not properly harvested and stored, wheat may also be infested with fungi such as aspergillus and fusarium, leading to consumption of harmful mycotoxins [3]. Thus, in looking for evidence of an adverse reaction to wheat, if one is looking exclusively for celiac disease or an IgE allergy to wheat, it is possible for a clinician to arrive at a false conclusion of safety.

\section{Gluten and Celiac Disease}

Gluten is made up of the storage proteins gliadin and glutenin, linked together by starch. In celiac disease, the Triticeae tribe of gliadin and glutenin proteins, including wheat, barley, and rye, triggers an immune response activated by dendritic cells in the proximal part of the small intestine. This leads to an inflammatory spectrum recognized first as small intestinal inflammation which then progresses through a degenerative process (Marsh Classification system 0-IIIa, $\mathrm{b}, \mathrm{c})$ to eventual total villous atrophy. $\mathrm{CD}$ is characterized by villous atrophy and positive serology for autoantibodies to tissue Transglutaminase 2 (tTG) and/or endomysium. Celiac disease is an autoimmune condition. It is characterized by autoantibody production (transglutaminase and/or endomysium), autoimmune enteropathy, and autoimmune comorbidities up to 30 times more prevalent than in the general population $[14,15]$.

Tissue transglutaminase autoantibodies detect CD with $95 \%$ sensitivity and specificity [16]. Tissue transglutaminase is an ubiquitous protein involved in a wide variety of cell processes and therefore has a role in wound healing, inflammation, autoimmunity, and others [17]. tTG is central to the pathogenesis of celiac disease. It potentiates the immunogenicity of gluten peptides in the small bowel through deamidation. Tissue transglutaminase is the main target antigen for EMA antibodies and tTG is therefore recommended as a primary screening test for CD [18]. In celiac disease, antibodies are also produced against endomysium, a structure of the smooth muscle connective tissue. Anti-endomysial antibodies show a sensitivity and specificity $>$ $95 \%$ for detecting total villous atrophy $\mathrm{CD}$, however its sensitivity is as low as $27 \%-31 \%$ with partial villous atrophy $[2,19,20]$.

The classical presentation of $\mathrm{CD}$ is diarrhea, steatorrhea, and weight loss, mainly reflecting the damage to the intestines. However it is more recently recognized as a multi-system disorder, affecting the nervous system, musculoskeletal system, cardiovascular system, skin, and liver [14]. There are many heterogeneous, non-specific symptoms of $\mathrm{CD}$, making it difficult to diagnose and earning its epithet as a "clinical chameleon." CD may manifest with gastrointestinal, heart, brain, liver, reproductive, or kidney symptoms [21,22].

Therefore, primarily suspecting $\mathrm{CD}$ based on gastrointestinal symptoms alone is in error. Clinicians should be aware that wheat-related disorders can present with dramatically different clinical presentations from one patient to another varying from gastrointestinal, metabolic, musculoskeletal, neuropsychiatric, reproductive and skin disorders (Table 1). For every celiac patient with gastrointestinal symptomatology, there are eight with extra-intestinal symptoms. In patients with recognized autoimmunity, it may be prudent to have an increased index of suspicion for a wheat-related disorder [23]. Delayed diagnosis of CD leads to cases with serious, long-term complications, such as osteoporosis, psychiatric disorders, infertility and reproductive disorders, ataxia, seizures, and cancer. Atypical and silent forms of $\mathrm{CD}$ further add to the difficulty of reaching an accurate diagnosis [14].

\begin{tabular}{|c|c|}
\hline General & $\begin{array}{c}\text { Weakness, lassitude, malaise, weight loss, short stature, failure to } \\
\text { thrive }\end{array}$ \\
\hline Gastrointestinal & $\begin{array}{l}\text { Diarrhea/constipation, anorexia, nausea and vomiting, flatulence } \\
\text { and abdominal distension, abdominal pain, motility disturbance, } \\
\text { glossitis/aphthous ulcers }\end{array}$ \\
\hline Metabolic & $\begin{array}{l}\text { Anemia features, bleeding tendency, edema, cramps/tetany, dental } \\
\text { enamel hyperplasia, malabsorption, malnutrition }\end{array}$ \\
\hline Musculoskeletal & Bone pain and fractures, myopathy, osteopenia, osteoporosis \\
\hline Neuropsychiatric & $\begin{array}{c}\text { Depression, anxiety, schizophrenia, paraesthesia, peripheral } \\
\text { neuropathy, cerebrospinal degeneration }\end{array}$ \\
\hline Reproductive & $\begin{array}{c}\text { Menstrual irregularities, recurrent miscarriages, abnormalities of } \\
\text { sperm morphology and motility, infertility, intrauterine growth } \\
\text { retardation }\end{array}$ \\
\hline Skin & Variety of rashes, petechiae \\
\hline
\end{tabular}

Table 1: Typical symptoms found in celiac disease and non-celiac gluten sensitivity [14].

\section{Non-Celiac Wheat Sensitivity and Non-Celiac Glu- ten Sensitivity}

While the antigenic specificity and pathogenic relevance of immunologic reactivity to gluten in celiac disease has been extensively researched, the immune response to non-gluten proteins of wheat has not been characterized. The main immunoreactive non-gluten antibody target proteins have been identified as serpins, purinins, $\alpha$-amylase/protease inhibitors, globulins and farinins. Assessment of reactivity toward purified recombinant proteins further confirmed the presence of antibody response to multiple specific antigens [24]. The conundrum of non-allergy, non-celiac response to the ingestion of wheat has been explored in the literature for over 40 years. Originally it was labeled as non-celiac gluten sensitivity. However, because non-gluten components of wheat, barley and rye may induce the disease, the more inclusive term, "non-celiac (non-allergy) wheat sensitivity", has been suggested [3]. NCGS and NCWS generally refer to a collection of non-specific symptoms in response to ingestion of gluten-containing cereals that resolve upon removal from the diet, in individuals for whom coeliac disease and IgE-mediated wheat allergy have been ruled out. A WRD may be associated with GI 
symptoms as well as numerous extra-intestinal symptoms [25]. There is now undisputable and increasing evidence for NCGS [4]. Its existence is well established in multiple double blind studies [26]. In a group of 200 patients referred to gastroenterologists for evaluation of a possible gluten-related disorder, $7 \%$ had celiac disease while the remaining $93 \%$ were classified as having non-celiac gluten sensitivity [27].

Studies evaluating NCGS have generally been performed in adults, although pediatric cases have been reported [28]. In a prospective multicenter study (38 Italian centers-27 adult gastroenterology, 5 internal medicine, 4 pediatrics, and 2 allergy-all recognized as referral centers and included in the register of the Italian Health Ministry for the diagnosis of gluten-related disorders), performed over 1 year, 391 new cases of NCGS to 340 new cases of celiac disease were identified, giving a ratio of 1.15:1 [26]. NCGS can present with variable gastrointestinal and extra-intestinal symptoms, as shown in table 1 . The most frequent gastrointestinal symptoms reported in the multicenter study were bloating and abdominal pain, found in $87 \%$ of females and in $83 \%$ of males. More than $50 \%$ of patients reported diarrhea, with the number of evacuations per day ranging from 3 to 10 , while $27 \%$ had alternating bowel habits and $24 \%$ had constipation. After bloating and abdominal pain, epigastric pain was the most frequent symptom, being found in $52 \%$ of patients, followed by nausea, aerophagia, gastroesophageal reflux disease and aphthous stomatitis in decreasing prevalence [26]. The most frequent extra-intestinal manifestations of NCGS were tiredness and lack of wellbeing, reported by $64 \%$ (female) and $68 \%$ (male) of the enrolled subjects. In addition, a high prevalence of neuropsychiatric symptoms including headache (54\%), anxiety (39\%), 'foggy mind' (38\%) and arm/leg numbness $(32 \%)$ were recorded. Other extra-intestinal manifestations emerging from the analysis of the survey responses were joint/muscle pain resembling fibromyalgia (31\%), weight loss (25\%), anemia (due to both to iron deficiency and low folic acid; $22 \%$ ), depression (18\%), dermatitis $(18 \%)$ and skin rash $(29 \%)$. None of these patients were positive for celiac disease [26]. Non-celiac wheat-related disorders may have higher rates of autoimmune processes, much like that found in celiac disease. In the most recent study to date comparing celiac disease, Non-Celiac Wheat Sensitivity and IBS, the incidence of a patient having elevated antibodies to self (ANA) with NCWS was $46 \%$ vs. $24 \%$ in celiac disease and $2 \%$ in IBS [29]. Although the pathophysiology of NCGS is being actively explored, the complete picture is still unknown. Gluten and glutenin peptides, distinct from those that initiate celiac disease, appear to trigger the innate and adaptive immune response in intestinal epithelia, dendritic cells, macrophages, and monocytes in NCGS [30-34]. It can present with intestinal and extraintestinal symptoms, yet standard serological tests are often negative, and genetic predisposition (HLA DQ2/8) is variable [4].

\section{Diagnostic Testing}

Historically, celiac disease was defined as total villous atrophy and therefore small intestinal biopsy has been acknowledged as the "gold standard" for diagnosis [35]. However, celiac disease, as is true of all autoimmune diseases, develops on a spectrum [36]. Total villous atrophy can be viewed as the "end stage" of an extended, activated immune response in the small intestine. As one of the following case studies will demonstrate, earlier (subclinical) stages in the development of autoimmunity provide a window of opportunity to address the activated, adaptive immune response before organ damage has progressed to the frank pathology and the diagnostic state [36]. Advances in diagnostic testing have yielded specific and sensitive serum tests for the detection of total-villous-atrophy CD: IgA tissue transglutaminase, IgA antiendomysial antibody, and $\operatorname{IgG}$ anti-deamidated gliadin peptide antibodies $[14,35,37]$. IgA tTG antibody is the most sensitive and specific serological marker of total villous atrophy CD [35]. Recent guidelines released by the European Society for Pediatric Gastroenterology, Hepatology, and Nutrition state that high anti-tTG antibody titers is sufficient for diagnosis [38]. In adults, an IgA tTG three to five-fold above normal is diagnostic of total villous atrophy and a biopsy is therefore not required [39]. North American 2005 diagnostic guidelines recommend testing children with symptoms of celiac disease, or an increased risk of celiac disease, using serum tTG. Those with high serum levels are referred to a pediatric gastroenterologist for an intestinal biopsy and if abnormal histology is observed, the patient should be treated with a strict gluten-free diet [40]. In 2012, the European Society for Pediatric Gastroenterology, Hepatology, and Nutrition reported that in a child with suspected celiac disease, a compatible HLA status, positive EMA, and tTG elevated more than 10-fold, the obligatory duodenal biopsy could be bypassed [41].

Wheat allergy is mediated by an IgE antibody response to allergens in wheat flour (such as gliadin, a-amylase/trypsin inhibitor, omega gliadins or a-purothionin), which trigger the release of histamine from basophils and mast cells [14,42]. Wheat allergy should be detectable with IgE antibody testing, although non-IgE-mediated wheat allergy does exist and may be indistinguishable from NCGS [43]. To identify the specific offending allergen, skin prick testing or serum IgE antibodies are good screening tests, but neither has optimal reliability. The sensitivity was $44 \%$ for skin testing and $56 \%$ for radioallergosorbent test, and the specificity was $67 \%$ for both tests [44]. Thus, screening for an immune-mediated ARF with a single category of immunoglobulin may not be adequate [44].

Ninety to ninety-five $\%$ of patients with $\mathrm{CD}$ are positive for HLADQ2 and $5-10 \%$ are positive for HLA-DQ8 genes, however newer evidence shows $7 \%$ of those with celiac disease will not carry either of these two genes [21]. Historically, the human leukocyte antigens (HLA-DQ2 and/or HLA-DQ8) have been considered diagnostic prerequisites for celiac disease. A variety of genetic markers may indicate a vulnerability to the celiac spectrum. To date, approximately $54 \%$ of the genetics of CD can be explained by HLA plus 57 non-HLA single nucleotide polymorphisms (Figure 1) [45]. Previously referred to exclusively as "the celiac genes", HLA-DQ2 and DQ8 are also found in $53 \%$ of NCGS cases [27]. Until recently, there have been no reliable biomarkers of non-celiac gluten sensitivity that have been universally accepted.

Historically, compelling evidence identifies a useful clinical role for immunoglobulin testing (IgG, $\operatorname{Ig} A, \operatorname{Ig} M)$ to multiple peptides of gluten [46]. Recently, Choung et.al., Have demonstrated novel sets of epitopes derived from gliadin which have a high degree of accuracy (99\% sensitivity and $100 \%$ specificity, $\mathrm{p}<0.001)$ in differentiating CD from controls, compared with standard serologic tests [46]. This method of ultra-high-density peptide microarray is proving broadly useful in identifying an immune reaction to wheat outside of the standard antigen screen of a wheat-related disorder. The relative noninvasiveness, broad availability, and versatility of the high-throughput 
Citation: O'Bryan T (2018) Review of Three Pediatric Wheat-Related Disorder Cases with Disparate Clinical Manifestations. J Gastroenterol Hepatology Res 3: 020 .

peptide microarrays make this technology well suited for incorporation into routine health care and also provide a promising new tool for biomarker discovery [47]. Immunochip analysis increased the number of independent non-HLA CD susceptibility single nucleotide polymorphisms to fifty-seven (Figure 1) [45].

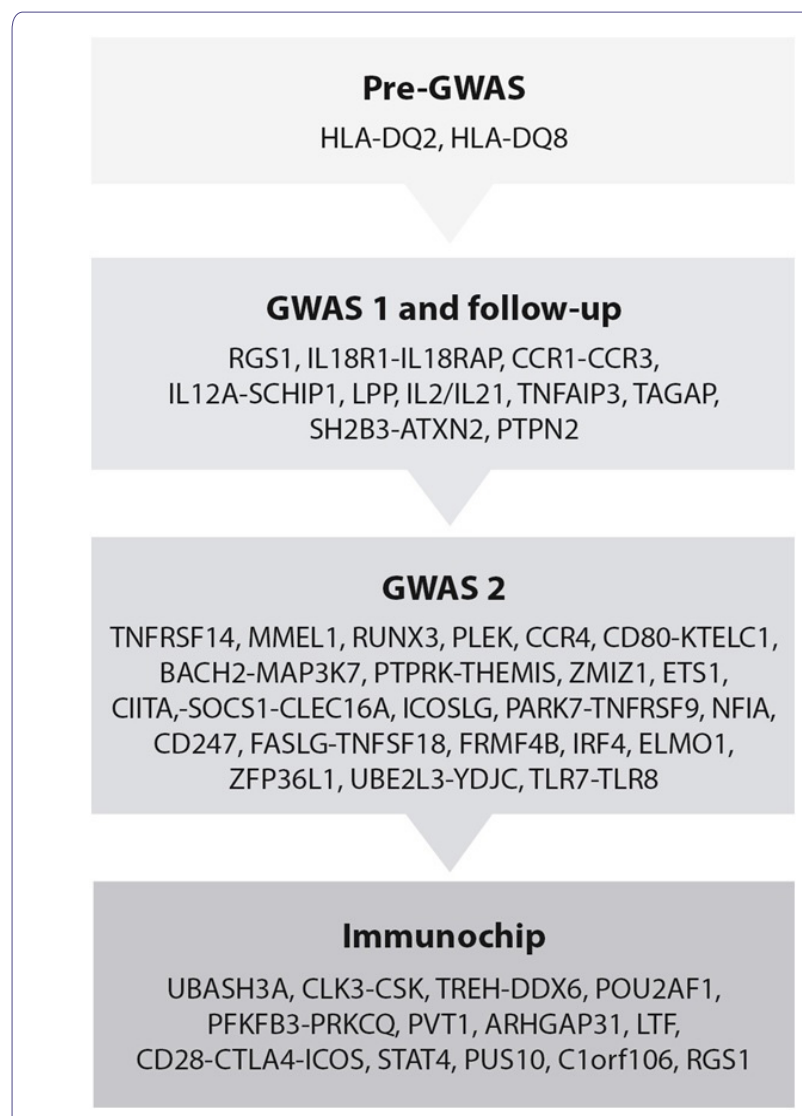

Figure 1: History of celiac disease genetics.

Immunochip analysis increased the number of independent non-HLA CD susceptibility single nucleotide polymorphisms to fifty-seven. Reproduced with permission [45].

\section{Clinical Case Analysis}

Here we describe three previously published, pediatric cases of wheat-related disorders (with and without enteropathy characteristic of celiac disease) whose clinical manifestations were widely disparate: type 1 diabetes, pediatric sclerosing cholangitis (liver failure), and conjunctival tumor with an assumed diagnosis of Kaposi's sarcoma. The cases were selected specifically for the varied and serious clinical pathologies observed in children and the lack of "hallmark" gastrointestinal symptoms that would have normally tipped off the practitioner to a wheat-related disorder. Two patients had CD and one had NCGS. Organ systems affected were the pancreas, liver, and eye and pathology resolved with a gluten free diet. This review analyzes the similarities and differences in these three cases and serves as a clinical lesson about the varied and unexpected aspects of wheat-related disorders, with or without celiac disease. Reference to the existing clinical literature and underlying mechanisms are discussed.

\section{Pediatric Type 1 Diabetes Mellitus without CD}

\section{Presentation and lab findings}

Sildorf and colleagues describe a 6-year-old boy who presented with Type 1 Diabetes Mellitus (T1DM) without evidence of celiac disease or gluten sensitivity [48]. He was admitted to the hospital with polydipsia, polyuria, blood glucose of $255.6 \mathrm{mg} / \mathrm{dL}$ (normal, 65-99)*, ketonuria, and hemoglobin A1C of $10.4 \%$ (normal, $<5.7 \%$; prediabetes, $5.7-6.4 \%$; diabetes, $>6.5 \%$ ). He did not have diabetic ketoacidosis. His glutamic acid decarboxylase antibodies were positive. He was negative for islet cell antibody and insulinoma associated antigen-2A. Gliadin antibodies, human transglutaminase and endomysium antibodies were negative so he was given the diagnosis of T1DM without celiac disease (or any other wheat-related disorder).

\section{Treatment and follow-up}

The patient was treated with insulin for five weeks (0.69 IE/ $\mathrm{kg} / 24 \mathrm{~h}$ ). Afterwards, blood glucose normalized so that the child was considered in the remission phase $(72-108 \mathrm{mg} / \mathrm{dL}) *$ and insulin was discontinued. HBA1c was $7.8 \%$. Eight weeks post-diagnosis (three weeks after insulin treatment concluded), the family instituted a gluten-free diet as an adjunctive treatment with the hopes that it might preserve Beta cell activity. The clinic was preparing a study of a gluten-free diet intervention so it was offered to the child, even though he did not have celiac disease. The diet was also low glycemic, average calorie $7,085 \mathrm{KJ} /$ day, and was split into six-seven small meals to be eaten throughout the day.

Twelve weeks after diagnosis and four weeks after dietary changes, HbAlc was $6.7 \%$ (Figure 2). At eight months post-diagnosis, and after a challenge meal, C-peptide was $1.74 \mathrm{ng} / \mathrm{mL}^{*}$ (normal 0.8-3.1) and proinsulin was $26 \mathrm{pmol} / 1$ (normal, 3-20 pmol/L). At 12 months post-diagnosis, C-peptide was $0.44 \mathrm{ng} / \mathrm{mL}^{*}$ and proinsulin was 15 $\mathrm{pmol} / \mathrm{l}$. Unfortunately, stimulated c-peptide remained low and declined each month. However, insulin adjusted $\mathrm{HbAlc}$ is a surrogate marker for residual Beta cell function and remained low, suggesting the child was indeed in remission [48]. Remission was defined as either $\mathrm{HbA} 1 \mathrm{c}<7.5 \%$, C-peptide above $0.91 \mathrm{ng} / \mathrm{mL},{ }^{*}$ a daily insulin requirement $<0.5$ units $/ \mathrm{kg} / 24 \mathrm{hr}$, or an insulin adjusted $\mathrm{HbAlc}<9$. GAD antibodies were not altered by the dietary changes.

Sixteen months after diagnosis, serum fasting insulin was 0.66 $\mathrm{uIU} / \mathrm{mL}^{*}$ (normal, $<25 \mathrm{mIU} / \mathrm{L}$ ) and blood glucose was normal at 73.8 $\mathrm{mg} / \mathrm{dL}^{*}$. Lipids were normal. Twenty months after diagnosis the patient still did not require insulin treatment. The authors stated in their conclusion, "At present time, the patient has been without daily insulin therapy for 20 months, a feature rarely seen in (diabetic) children of this age".

*Laboratory data has been converted to conventional units, including reference ranges, for a North American readership. See the original case report for data recorded in SI units [48]. 

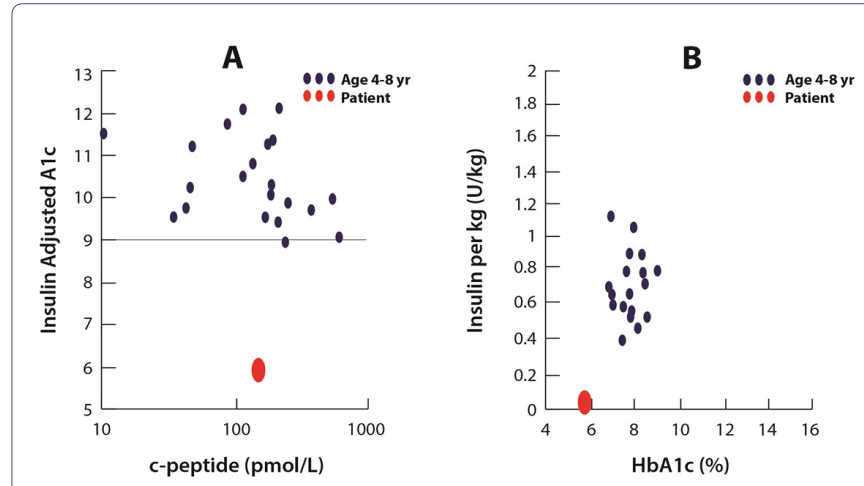

Figure 2: T1DM child (red mark) on a GFD achieved remission when compared to similar children (black marks).

The child showed (2a) lower insulin adjusted A1c and stimulated $\mathrm{C}$-peptide than 21 other comparable children. Insulin adjusted A1c below $9 \%$ places him in remission status. The patient's insulin requirement (2b) and $\mathrm{HbA} 1 \mathrm{c}$ were lower than his cohort after 12 months [48]. Reproduced with permission from BMJ Publishing Group Ltd.

\section{Type 1 Diabetes Mellitus and Wheat-Related Disor- ders}

Generally the diagnosis of T1DM precedes the onset of CD [49]. Ten percent of those diagnosed with T1DM will show evidence of celiac disease on duodenal biopsy [49]. In a large group of children with diabetes followed over six years, $60 \%$ were seropositive for celiac at the time T1DM was diagnosed and the remaining $40 \%$ were diagnosed with celiac four years later [50,51]. In adults with T1DM, $42 \%$ were found to have $\mathrm{CD}$ within 10 years of diagnosis and other studies show that serology is positive for CD 15 years after diagnosis [35]. While T1DM patients are twenty times more likely to have CD, the reverse is not true. Patients with $\mathrm{CD}$ are not more likely to have T1DM [49,51].

The co-occurrence of celiac disease and T1DM are best explained by their shared genetic underpinnings, particularly the major histocompatibility complex class II antigen DQ2, encoded by DQA $1 * 501$ and DQB1*201 [52]. Other, non-HLA genetics have also been found in celiac disease and T1DM [35].

The authors concluded that dietary changes, especially a gluten-free diet, led to a long, highly unusual, remission period of 20 months, without insulin therapy, in a child with T1DM. The child had a low C-peptide which suggested low levels of insulin production by the pancreas and higher risk of T1DM and elevated blood glucose. However, with dietary treatment, insulin sensitivity was enhanced and the C-peptide level and $\mathrm{HbA} 1 \mathrm{c}$ levels remained stable. Blood glucose and insulin requirements normalized, placing the child in remission. To the author's knowledge, this represents the first human trial of a gluten-free diet to effectively treat a patient with type 1 diabetes.

There are mixed results as to the efficacy of a GFD in lowering hemoglobin A1c [35]. However, it poses no risks and may have helped to prolong remission and may have even preserved Beta cells in this case of T1DM [48].
The authors stated these learning points [48]:

- Gluten-free diet prolongs remission

- Gluten-free diet increases insulin sensitivity

- Gluten-free diet is safe and acceptable

Unlike the other case reports, the 6-year-old with type 1 diabetes was negative for human transglutaminase, endomysium, and gliadin antibodies and he was therefore negative for CD. Perhaps over 5-10 years, he would have eventually developed frank CD by standard diagnostic tests, as do other patients with T1DM. He fits the current criteria for non-celiac wheat sensitivity [43]. He never would have been trialed on a GFD except by happenstance. This raises the question: How many other children like him might derive benefit from a GFD, prior to developing serological indicators of a wheat-related disorder?

Screening for a wheat-related disorder in patients with T1DM is advisable, though guidelines vary [49]. International guidelines call for screening of T1DM patients for CD at the time of diagnosis and then subsequently every five years, however the American College of Gastroenterology Guidelines and Canadian guidelines encourage CD screening only in the presence of suggestive symptoms [35]. However, symptoms are often absent and these criteria could therefore miss $40-60 \%$ of cases who have mild or absent gastrointestinal symptoms [35]. Classic celiac disease symptoms and histopathological findings are not sufficient to be considered exclusive indicators of celiac disease in children with T1DM and Down's syndrome. Instead, authors recommend systematic serological screening because of the high prevalence of $\mathrm{CD}$ in these groups [50].

In type 1 diabetes, autoimmune disease destroys pancreatic Beta cells, causing permanent dependence on insulin and further negative complications affecting quality of life and life expectancy. If residual Beta cells can be preserved at the time of diagnosis, it can result in better short- and long-term outcomes [53]. When the onset of T1D is delayed, Beta cell function is better, there is a longer period of time preceding diagnosis, insulin autoantibodies are lower, patients are less frequently positive for HLA class II genes, metabolic function is preserved, and hA1C is lower at the time of diagnosis [54]. Early intervention with a GFD in those with wheat-related disorders could arrest or reverse disease processes and improve health throughout the lifespan.

\section{Pediatric Sclerosing Cholangitis (Liver Disease) with CD}

\section{Presentation and lab findings}

An 11-year-old girl was referred to a Children's Hospital for worsening liver failure [55]. She had suffered with fatigue, anorexia, and poor growth for three years. For one month prior she complained of jaundice and abdominal distention associated with mild itching. She had failure to thrive, being at the $3^{\text {rd }}$ percentile for growth and height. She was pale, wasted, had clubbed fingers, and palmar erythema. She had splenomegaly and severe ascites. The liver was impalpable. She was negative for diarrhea, vomiting, fever, and had not taken herbal or medical drugs.

Laboratory testing showed the following elevations: liver enzymes including ALT at $84 \mathrm{U} / \mathrm{L}$, total bilirubin $98.7 \mathrm{umol} / \mathrm{L}$ (normal, 3-17), direct bilirubin $58.3 \mathrm{umol} / \mathrm{L}(0-3 \mathrm{umol} / \mathrm{L})$, alanine aminotransferase was 200 (normal, 30-65 U/L). Gamma-glutamyltransferase was 
Citation: O'Bryan T (2018) Review of Three Pediatric Wheat-Related Disorder Cases with Disparate Clinical Manifestations. J Gastroenterol Hepatology Res 3: 020 .

$111 \mathrm{U} / \mathrm{L}$ (normal, 7-32), clotting studies showed an international normalized ratio (INR) of 2.7, and albumin was $16 \mathrm{~g} / \mathrm{L}$ (normal 35-50 $\mathrm{gm} / \mathrm{L}$ ). She was anemic with hemoglobin of $9.4 \mathrm{gm} / \mathrm{L}$ (normal, $11.1-$ 15.9). Extensive laboratory testing for metabolic, endocrine diseases; viral hepatitis, Wilson disease, and alpha-1-antitrypsin deficiency were unremarkable. No other pertinent genetic tests were reported. Total immunoglobulin $\mathrm{G}$ was elevated at $23 \mathrm{gm} / \mathrm{L}$ (3.7-15). Celiac disease was suspected and tissue transglutaminase antibodies were measured at 385 units (normal, 0-20 units). Small intestinal biopsy showed total villous atrophy and crypt hyperplasia, characteristic of celiac disease. Ultrasound showed a coarse, shrunken, nodular liver with mild splenomegaly and gross ascites. There was beading and narrowing of the bile ducts consistent with sclerosing cholangitis. Liver biopsy revealed bridging fibrosis, portal tract expansion due to lymphocytes, plasma cells, and neutrophils. Bile duct proliferation and periductular fibrosis were also observed. She was diagnosed with Primary Sclerosing Cholangitis (PSC), a condition of swollen, inflamed bile ducts, leading to scar tissue and damage, inside and outside of the liver [56]. PSC is a chronic cholestatic liver disease of unknown cause, leading to inflammation and fibrosis of the biliary tree [57]. It results in end-stage liver disease, and is among the most common indications for liver transplantation in Europe and the United States, resulting in a shortened life span $[58,59]$. PSC significantly decreases survival. The median (50\%) survival free of liver transplantation was 12.7 years [60].

\section{Treatment and follow-up}

The child was treated with ursodeoxycholic acid $(20 \mathrm{mg} / \mathrm{kg} /$ day $)$ and a gluten-free diet for life. She was prescribed prednisone $(1 \mathrm{mg} /$ $\mathrm{kg}$ /day) for three months which was then tapered down to $2.5 \mathrm{mg}$ / day and discontinued at 6 months. After three months, liver enzymes normalized completely. The serum tissue transglutaminase antibodies were completely negative at 6 months. Four years later, liver function tests were normal and the tissue transglutaminase antibodies were still negative. However, abdominal ultrasound continued to show evidence of liver damage: a heterogeneous, coarse, shrunken and nodular liver. Serum bile acid and gamma-glutamyltransferase levels were normal. Liver autoantibodies were negative. Sclerosing cholangitis improved with a gluten-free diet, steroids (3 months) and ursodeoxycholic acid.

\section{Liver Disease and Wheat-Related Disorders Com- mentary}

\section{Liver disease and histology in CD}

Of the extraintestinal manifestations of $\mathrm{CD}$, liver injury is very common [22], especially primary biliary cirrhosis and a mild, silent hepatitis often referred to as "celiac hepatitis" [61-63]. Hepatobiliary complications are seen in cases of gastrointestinal pathology, perhaps due to intestinal permeability brought on by the ingestion of gluten $[61,64]$, contaminating portal blood flow [65], putting the liver in direct contact with nutrients, toxins, bacteria, lipopolysaccharides, inflammatory cytokines, and immunocytes from the gastrointestinal tract [64]. Liver abnormalities detected by biopsy in CD patients have been variable: no abnormality detected, non-specific hepatitis, or even severe changes such as fibrosis and cirrhosis [62]. The most common liver findings in celiac disease are isolated hypertransaminasemia with nonspecific histologic changes in a liver biopsy [63]. Hypertransaminasemia has been seen at the time of diagnosis in $40 \%$ of adults and $54 \%$ of children with classic CD $[66,68]$. However, only $9 \%$ of patients with $\mathrm{CD}$ have chronically elevated, unexplained, liver enzymes [68]. Hypertransaminasemia has been shown to completely resolve with a GFD in patients with CD [22,62].

Chronic, untreated CD may lead to severe liver damage such as cryptogenic chronic hepatitis or liver cirrhosis requiring liver transplantation [22]. GFD can help to avoid liver transplantation, resolve hepatitis, and even reverse liver damage $[55,62]$. A GFD leads to normalization of serum transaminases in $75 \%$ to $95 \%$ of patients with $\mathrm{CD}$, usually within a year of good adherence to the diet (Table 2) $[67,69,70]$. All the patients with nonspecific changes in the liver histology and a follow-up liver biopsy normalized the histological changes after adherence to a GFD $[66,70,71]$. This is why reversible, wheat-related liver damage has been called celiac hepatitis [72].

\begin{tabular}{|c|c|c|c|}
\hline Reference & Cases & $\begin{array}{c}\text { Abnormal Liver } \\
\text { Tests (\%) }\end{array}$ & $\begin{array}{c}\text { Responses to a Gluten-Free } \\
\text { Diet (\%) }\end{array}$ \\
\hline Hagander et al. [66] & 53 & 39 & N/A \\
\hline Bardella et al. [67] & 158 & 42 & 95 \\
\hline Bonamico et al. [68] & 65 & 57 & N/A \\
\hline Novacek et al. [69] & 176 & 40 & 96 \\
\hline Jacobsen et al. [70] & 171 & 47 & 75 \\
\hline
\end{tabular}

Table 2: Liver Chemistry tests are abnormal in patients with celiac disease and are responsive to a gluten-free diet. Responses to a gluten-free diet are defined by complete normalization of liver chemistry tests. (Reproduced with permission [63]).

\section{Autoimmune liver disease}

$\mathrm{CD}$ is associated with autoimmune liver diseases: primary biliary cirrhosis, autoimmune hepatitis, and primary sclerosing cholangitis. This association may be due to the HLA genes DQA1*0501 and DQB $1 * 0201$. Figure 3 shows one possible mechanism for the liver injury seen in celiac disease. Antinuclear antibodies and smooth muscle antibodies have been found in $20 \%$ to $60 \%$ of patients with autoimmune sclerosing cholangitis (as is the case in celiac disease), and could represent an immunopathogenic link between the two conditions [73].

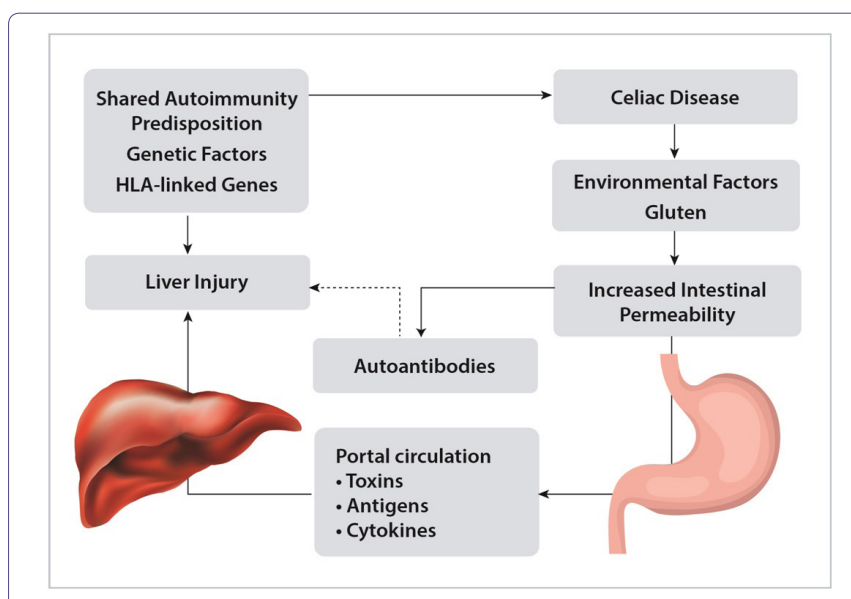

Figure 3: One possible mechanism for liver injury in cases of celiac disease.

Genetic factors and an environmental trigger (gluten) may work together to set off intestinal permeability, generation of autoantibodies, and liver injury. Reproduced with permission [63]. 

020 .

An association between CD and PSC was first described in 1988 [74]. A large, general population-based study from Sweden suggested that the prevalence of PSC increased 4- to 8-fold in patients with CD compared to those without CD [75]. Pediatric cases of CD with PSC have shown celiac disease to respond to a GFD, but not primary sclerosing cholangitis [74]. Given the severe liver damage seen in children with $\mathrm{CD}$, researchers recommended that children with recent onset of celiac disease should be checked for liver function routinely and likewise, children with severe liver damage should be worked up for celiac disease [76]. According to Al-Hussaini and colleagues, only five other cases of pediatric liver failure due to celiac disease had been reported in the literature as of 2013 [55]. The etiology of sclerosing cholangitis is unknown. It is a chronic and progressive inflammatory disease [77]. Gradual autoimmune damage of the biliary tree leads to irreversible damage to bile ducts, persistent jaundice, ascites, varices, cholestasis, cirrhosis, liver failure, and death or liver transplantation within $10-20$ years $[56,73,77]$. It is normally associated with inflammatory bowel disease and sometimes associated with celiac disease, chronic pancreatitis, diabetes mellitus, rheumatoid arthritis, or sarcoidosis [56,57]. Treatments are usually cholestyramine, ursodeoxycholic acid, fat-soluble vitamins, antibiotics for associated infection, and immune suppressant steroids. Surgical procedures are used to open up strictures of bile ducts in the liver and liver transplant is used for patients with end-stage liver disease [57]. There are no known treatments that bring about full remission from PSC [73,77].

Al-Hussaini and colleagues found that a gluten-free diet was the pivotal treatment for an 11-year old girl with liver disease and they concluded that it should be a part of routine screening in cases of unexplained liver disease. Because of the severity of the liver disease in this case, and unsure of the etiology, physicians treated this 11-yearold with prednisone and ursodeoxycholic acid, which are standard treatments for autoimmune sclerosing cholangitis and primary sclerosing cholangitis, respectively.

However, pharmacotherapy did not prove to be necessary. Ursodeoxycholic acid and steroids do not lead to full resolution of disease or would have required continued treatment to produce long-term clinical relief [55]. In contrast, for this 11-year-old girl, prednisone could be fully discontinued six months later and all tests remained normal four years later, strongly suggesting that $\mathrm{CD}$ was the source of the liver disease. GFD did not reverse damage to the liver, as she "continued to show a heterogeneous, coarse, shrunken, and nodular liver" on follow-up. The authors suggested that "celiac-associated sclerosing cholangitis" might be an appropriate label for this case and that CD may be a treatable cause of liver failure [55].

\section{Pediatric Conjunctival Tumor with CD}

\section{Presentation and lab findings}

Tuncer et al., described a 3-year-old girl with a hemorrhagic conjunctival lesion on the right eye [78]. She had the reddish lesion for three months. It was not responsive to topical steroids and was referred for second opinion. Clinical history included early cessation of breastfeeding, intolerance to baby foods, abdominal distention for two months, and anorexia. She was below normal weight and height. She had recurrent serous otitis media (fluid in the middle ear) which had been treated with antibiotics, but the cause was unknown. She had undergone small intestinal biopsy due to suspicion of celiac disease at another clinic.

The child had 20/20 vision in both eyes. But under examination by slit-lamp, there was a reddish, raised, "highly vascular spider-like lesion" on the superior bulbar conjunctiva of the right eye. It measured $12 \times 4 \times 2 \mathrm{~mm}$ (Figure 4A). The presumed diagnosis was conjunctival Kaposi's Sarcoma (KS). Kaposi's sarcoma is a cancer that grows under the skin, and in the lining of the nose, mouth and throat. Abnormal patches of tissue may be red or pink and painful. Kaposi's sarcoma is common in patients with immunosuppression, such as HIV and AIDS. However the child was negative for HIV. She showed elevated anti-gliadin and anti-endomysial antibodies (IgA). Intestinal biopsy showed partial villous atrophy, crypt hyperplasia, and intraepithelial lymphocytosis, diagnostic of celiac disease. The mother showed high levels of autoantibody titers for CD.

\section{Treatment and follow-up}

The patient initiated a gluten-free diet. No other protocols were initiated. After one week of GFD, the lesion gradually regressed. After two months on a GFD, the conjunctival lesion disappeared. At nine months follow-up the patient was completely asymptomatic and there was no recurrence of the ocular lesion.

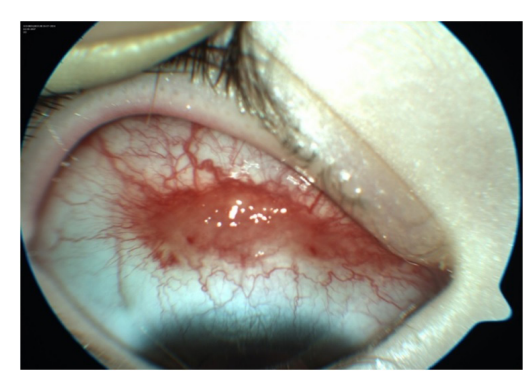

(A) At presentation.

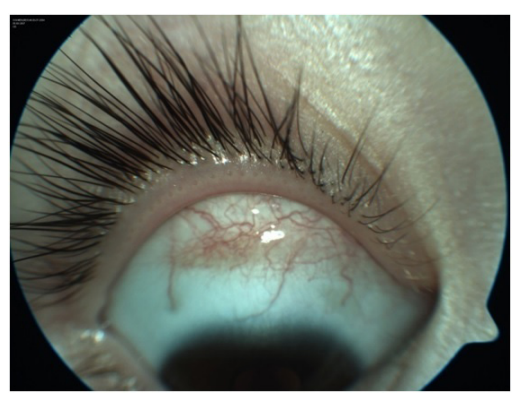

(B) After one week on a gluten-free diet.

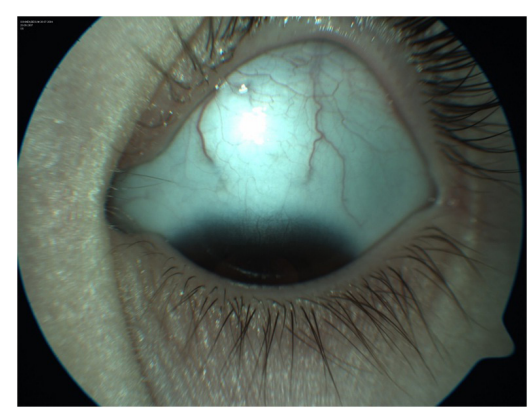

(C) After two months on a gluten-free diet.

Figure 4: (A) Image of a hemorrhagic conjunctival lesion on the right eye of a 3-year-old girl. After one week on a gluten-free diet, the lesion spontaneously regressed (B). After two months on a gluten-free diet, the conjunctival lesion had completely disappeared (C). Reproduced with permission from the Indian Journal of Opthalmology and the principal author [78]. 
The authors concluded: "We present a very unusual conjunctival tumor in a patient with $\mathrm{CD}$ that showed complete regression by a gluten-free diet. The precise pathological nature of this conjunctival lesion remains unknown due to the lack of histopathological confirmation. However, prompt regression of the conjunctival lesion during gluten-free diet suggests a possible relationship to CD and an autoimmune process".

\section{Kaposi's Sarcoma and Wheat-Related Disorders Commentary}

A 3-year-old girl had a hemorrhagic conjunctival lesion diagnosed as Kaposi's Sarcoma (KS), shortly before receiving the diagnosis of $\mathrm{CD}$. Maintenance of a GFD led to spontaneous regression of assumed conjunctival Kaposi's sarcoma [78]. CD was determined by intestinal biopsy. However, the diagnosis of KS was not confirmed by biopsy of the tumor because the parents did not want general anesthesia for their daughter [78].

The mechanism whereby CD led to Kaposi's sarcoma in this 3 -year-old is unknown. Authors concluded that CD let to an acquired autoimmune comorbid dysfunction, causing a lesion in the right eye with spider-like vascular extensions and subconjunctival hemorrhagic spots [78]. They postulated that anti-gliadin antibodies and/or circulating immune complexes deposited in the eye and affected the arrangement of capillary channels [78].

Neurological and psychiatric disorders have been noted in wheat-related disorders, suggesting that nerve tissue is damaged during the disease process $[79,80]$. In $\mathrm{CD}$, gliadin antibodies may cross react with aquaporin, affecting the nervous system, the eye, and other tissues such as the gut [81]. Aquaporins are a class of cellular water channels found throughout the body [82]. Aquaporin channels may be thought of as a component of the "scaffolding architecture" inside the cell, especially in the nervous system. In the brain, they are responsible for water exchange, maintaining homeostasis, electrical activity, and neuronal signal transmission [83]. AQP4 is the most abundant water channel in the CNS, and is highly concentrated on the brainstem, spinal cord, diencephalon, hypothalamus, and optic nerves [82]. Molecular mimicry between gliadin peptides and aquaporin-4 may contribute to neuromyelitisoptica, an autoimmune inflammatory condition of the central nervous system, mainly affecting the spinal cord and optic nerves $[79,84,85]$.

\section{Discussion}

These case studies show that a wheat-related disorder (with or without enteropathy) was related to the development of T1DM, liver disease, and a conjunctival tumor with a presumed diagnosis of Kaposi's sarcoma, in three different children and a GFD arrested or reversed the disease processes. These cases demonstrate a glimpse of the varied clinical presentations, and varied pathogenesis, of wheat-related disorders in pediatric patients. Gastrointestinal symptoms, commonly believed to characterize celiac disease, were largely absent in all three patients.

\section{Mechanisms of disease}

Proteins in gluten can promote the initiation, development, and propagation of autoimmune disease [14], with or without celiac disease. The classical paradigm of autoimmune pathogenesis involving a specific genetic makeup and exposure to environmental triggers has been challenged by the addition of a third element: the loss of intestinal barrier function [86]. This triad, or "perfect storm", of genetic vulnerability, an environmental trigger (in the case of $\mathrm{CD}$, gluten), and pathogenic intestinal permeability creates an opportunity for intervention before end-stage autoimmune disease develops [52]. It provides a leverage point where by re-establishing intestinal barrier function can arrest the autoimmune process and minimize the impact of genetic and environmental triggers [87].

The case of T1DM was likely due to an underlying autoimmune process triggered by wheat in take, even though gliadin, transglutaminase and endomysium antibodies were negative. This child qualified for the diagnosis of NCWS [3]. As gliadin sensitivity was negative, he may have been reacting to other peptides in gluten, not just gliadin. Poorly digested wheat may contain over 60 immunogenic peptides [88]. Non-gluten antigenic proteins found in wheat include serpins, purinins, $\alpha$-amylase/protease inhibitors, globulins, and farinins [24]. The child was positive for GAD antibodies and remained positive even after a GFD [48]. Sclerosing cholangitis in the 11-year-old girl with CD may have also been an autoimmune process. Common, predisposing genetic factors (DQA1*501 and DQB1*201) may explain the increased prevalence of T1DM and liver disease in patients with $\mathrm{CD}$ and in the increased susceptibility of these children to these conditions.

Gliadin initiates intestinal permeability in all individuals [65]. It is a proven cytotoxic protein, even for those without wheat-related disorders [4]. At the cellular level, it rearranges the cytoskeleton via zonulin, causes apoptosis, inhibits cell growth, changes the redox balance and enhances intestinal permeability by damaging tight junctions in the gastrointestinal lining [4]. Intestinal permeability may have therefore been a symptom in all three cases, although no testing was done to confirm this. The 3-year-old with a conjunctival tumor had a short duration of breastfeeding and multiple rounds of antibiotics for otitis media, suggesting microflora disturbance and vulnerability to pathogenic intestinal permeability. This could have contributed to the development of $\mathrm{CD}$, accelerated vulnerability to, or exacerbated the condition. Antibiotics and reduced duration of breastfeeding have been shown to increase the risk of developing CD $[89,90]$ and $\mathrm{CD}$ patients have abnormal microflora populations which continually stresses the epithelial lining in the GI tract $[89,91]$.

Systemic damage due to CD may occur by a number of inflammatory pathways. In the intestinal lamina propria, gliadin triggers an increase in Intraepithelial Lymphocytes (IELs) which release inflammatory cytokines such as IFN-gamma, IL-6, and TNF-alpha. Additional macrophages and fibroblasts are recruited to the site leading to inflammation and destruction of the intestinal lining [35]. Higher levels of these cytokines and interleukins can be found in the systemic circulation of subjects with untreated CD. A GFD can lower the levels of these inflammatory markers and therefore the atherosclerotic and endothelial damage that they incur [35].

In CD, the number of gliadin-specific HLA-DQ2-restricted T-lymphocytes increases and antibodies against gliadin increase in circulation, potentially affecting the function of many organs [22]. Tissue transglutaminase- 2 antibody affects endothelial cell adhesion and cell function and can cause vascular damage. tTG in liver diseases is associated with fibrogenesis, inflammation, and tissue repair. Patients with liver disease and celiac disease showed a higher expression of tTG in liver tissue [22]. 


\section{Conclusion}

These three pediatric cases of wheat-related disorders (with or without celiac disease) were chosen because they demonstrate widely disparate, serious clinical manifestations in children: liver failure, type 1 diabetes mellitus, and a conjunctival tumor with a presumed diagnosis as Kaposi's sarcoma. The prognoses for these children, had they not been treated with a GFD, were poor. Autoimmune disease, complications, and even death could have followed. The child with type 1 diabetes would have had high $\mathrm{HbA}$ 1 cand high glucose (like his cohort). He would have likely developed full-blown type 1 diabetes and perhaps other autoimmune conditions over time. The child with primary sclerosing cholangitis would have progressed to liver failure and possibly death. It is reasonable to assume that the child with Kaposi's sarcoma would have worsened and eventually developed symptoms of $\mathrm{CD}$ and/or other autoimmune comorbidities.

Wheat-related disorders are systemic conditions. While there is increasing awareness that WRDs can manifest with extraintestinal symptoms, clinicians still rely too heavily on the presence of gastrointestinal symptoms to suspect a WRD. Patients with WRDs, who do not have gut symptoms, remain unidentified. The impact of a wheat-related disorder (with or without celiac disease) can manifest in any organ or system and has been shown to impact cardiovascular disease and malignant neoplasms, autoimmune diseases, connective tissue diseases, allergies, inflammatory bowel disease, nephritis, and even infections [22,35,92]. Previous antecedents (including stressors and exposures) and genetic susceptibilities can influence how gluten sensitivity manifests in the body. These cases showed wheat-related pathogenesis affecting the liver, pancreas, or eye, without notable gastrointestinal symptoms. These cases and the medical literature suggest that hypertransaminasemia, unexplained liver pathology, intestinal permeability, and autoimmune conditions, especially T1DM, warrant further investigation for an underlying wheat-related disorder.

Classic symptoms of CD have been shown to poorly correspond with histopathological findings and are insufficient indicators of CD. Given that hundreds of protein interactions define a chronic disease, not a defect in any single pathway, a wheat-related disorder can present with a variety of symptoms due to its profound impact on the microbiome, and its systemic inflammatory and immunogenic impacts on the body [93]. These cases illustrate that "any symptom" in the body may be caused by a sensitivity to an environmental trigger (in this case gluten), initiating an inflammatory cascade. It is not restricted to one disease in one single organ system. For this reason, in patients with unexplained symptoms who do not improve with standard therapies, it may be prudent to screen for serological indicators of wheat-related disorders.

\section{Acknowledgements}

Special thanks to the authors of the case reports that made this analysis possible. Appreciation is owed to BMJ Case Reports, Hepatology, and the Indian Journal of Opthalmology for permission to reuse figures and tables.

\section{References}

1. Bischoff S, Crowe SE (2005) Gastrointestinal food allergy: new insights into pathophysiology and clinical perspectives. Gastroenterology 128 1089-1113.
2. Lebwohl B, Murray JA, Verdú EF, Crowe SE, Dennis M, et al. (2016) Gluten Introduction, Breastfeeding, and Celiac Disease: Back to the Drawing Board. Am J Gastroenterol 111: 12-14.

3. Schuppan D, Pickert G, Ashfaq-Khan M, Zevallos V (2015) Non-celiac wheat sensitivity: differential diagnosis, triggers and implications. Best Pract Res Clin Gastroenterol 29: 469-476.

4. Fasano A, Sapone A, Zevallos V, Schuppan D (2015) Nonceliac gluten sensitivity. Gastroenterology 148: 1195-1204.

5. Molina-Infante J, Santolaria S, Sanders DS, Fernández-Bañares F (2015) Systematic review: noncoeliac gluten sensitivity. Aliment Pharmacol Ther 41: 807-820.

6. Pellegrina CD, Perbellini O, Scupoli MT, Tomelleri C, Zanetti C, et al. (2009) Effects of wheat germ agglutinin on human gastrointestinal epithelium: insights from an experimental model of immune/epithelial cell interaction. Toxicol Appl Pharmacol 237: 146-153.

7. Miyake K, Tanaka T, McNeil PL (2007) Lectin Lectin-Based Food Poisoning: A New Mechanism of Protein Toxicity. PLoS ONE 2: 687.

8. Junker Y, Zeissig S, Kim SJ, Barisani D, Wieser H, et al. (2012) Wheat amylase trypsin inhibitors drive intestinal inflammation via activation of toll-like receptor 4. J Exp Med 209: 2395-2408.

9. Shepherd SJ, Parker FC, Muir JG, Gibson PR (2008) Dietary triggers of abdominal symptoms in patients with irritable bowel syndrome: randomized placebo-controlled evidence. Clin Gastroenterol Hepatol 6: 765-771.

10. Murray K, Wilkinson-Smith V, Hoad C, Costigan C, et al. (2014) Differential effects of FODMAPs (fermentable oligo-, di-, mono-saccharides and polyols) on small and large intestinal contents in healthy subjects shown by MRI. Am J Gastroenterol 109: 110-119.

11. Halmos EP, Power VA, Shepherd SJ, Gibson PR, Muir JG (2014) A diet low in FODMAPs reduces symptoms of irritable bowel syndrome. Gastroenterology 146: 67-75.

12. Biesiekierski JR, Peters SL, Newnham ED, Rosella O, Muir JG et al. (2013) No effects of gluten in patients with self-reported non-celiac gluten sensitivity after dietary reduction of fermentable, poorly absorbed, shortchain carbohydrates. Gastroenterology 145: 320-328.

13. Vojdani A, O’Bryan T, Green JA, Mccandless J, Woeller KN, et al. (2004) Immune response to dietary proteins, gliadin and cerebellar peptides in children with autism. Nutr Neurosci 7: 151-161

14. O’Bryan T, Ford R , Kupper C (2012) Celiac Disease and Non-Celiac Gluten Sensitivity. In: Kohlstadt I (ed.). Advancing Medicine with Food and Nutrients (2ndedn). CRC Press, Florida, USA.

15. Vojdani A, O’Bryan T, Kellermann GH (2008) The Immunology of Gluten Sensitivity beyond the Intestinal Tract. European Journal of Inflammation 6: 49-57.

16. Rubio-Tapia A, Hill ID, Kelly CP, Calderwood AH, Murray JA, et al (2013) ACG clinical guidelines: diagnosis and management of celiac disease. Am J Gastroenterol 108: 656-676.

17. Nurminskaya MV, Belkin AM (2012) Cellular functions of tissue transglutaminase. Int Rev Cell Mol Biol 294: 1-97.

18. Schuppan D, Zimmer K-P (2013) The Diagnosis and Treatment of Celiac Disease. Dtsch Arztebl Int 110: 835-846.

19. Kaswala DH, Veeraraghavan G, Kelly CP, Leffler DA (2015) Celiac Disease: Diagnostic Standards and Dilemmas. Diseases 3: 86-101.

20. Rostami K, Kerckhaert J, Tiemessen R, von Blomberg BM, Meijer JW (1999) Sensitivity of antiendomysium and antigliadin antibodies in untreated celiac disease: disappointing in clinical practice. Am J Gastroenterol 94: 888-894. 
21. Fasano A (2003) Celiac disease--how to handle a clinical chameleon. N Engl J Med 348: 2568-2570.

22. Drastich P, Honsová E, Lodererová A, Jarešová M, Pekáriková A, et al. (2012) Celiac disease markers in patients with liver diseases: A single center large scale screening study. World J Gastroenterol 18: 6255-6262.

23. Fasano A, Catassi C (2001) Current approaches to diagnosis and treatment of celiac disease: an evolving spectrum. Gastroenterology 120: 636-651.

24. Huebener S, Tanaka CK, Uhde M, Zone JJ, Vensel WH, et al. (2015) Specific nongluten proteins of wheat are novel target antigens in celiac disease humoral response. J Proteome Res 14: 503-511.

25. Uhde M, Ajamian M, Caio G, Giorgio RD, Indart A, et al. (2016) Intestinal cell damage and systemic immune activation in individuals reporting sensitivity to wheat in the absence of coeliac disease. Gut 65: 1930-1937.

26. Volta U, Bardella MT, Calabrò A, Troncone R, Corazza GR, et al. (2014) An Italian prospective multicenter survey on patients suspected of having non-celiac gluten sensitivity. BMC Med 12: 85.

27. Aziz I, Lewis NR, Hadjivassiliou M, Winfield SN, Rugg N et al. (2014) A UK study assessing the population prevalence of self-reported gluten sensitivity and referral characteristics to secondary care. Eur J Gastroenterol Hepatol 26: 33-39.

28. Francavilla R, Cristofori F, Castellaneta S, Polloni C, Albano V, et al. (2014) Clinical, serologic, and histologic features of gluten sensitivity in children. J Pediatr 164: 463-467.

29. Carroccio A, D’Alcamo A, Cavataio F, Soresi M, Seidita A, et al. (2015) High Proportions of People With Nonceliac Wheat Sensitivity Have Autoimmune Disease or Antinuclear Antibodies. Gastroenterology 149: 596603.

30. Jelínková L, Tucková L, Cinová J, Flegelová Z, Tlaskalová-Hogenová $\mathrm{H}$ (2004) Gliadin stimulates human monocytes to production of IL-8 and TNF-alpha through a mechanism involving NF-kappaB. FEBS Lett 571: $81-85$.

31. Nikulina M, Habich C, Flohé SB, Scott FW, Kolb H (2004) Wheat gluten causes dendritic cell maturation and chemokine secretion. J Immunol 173: 1925-1933.

32. Rakhimova M, Esslinger B, Schulze-Krebs A, Hahn EG, Schuppan D, et al. (2009) In vitro differentiation of human monocytes into dendritic cells by peptic-tryptic digest of gliadin is independent of genetic predisposition and the presence of celiac disease. J Clin Immunol 29: 29-37.

33. Lammers KM, Lu R, Brownley J, Lu B, Gerard C, et al. (2008) Gliadin induces an increase in intestinal permeability and zonulin release by binding to the chemokine receptor CXCR3. Gastroenterology 135: 194-204.

34. Thomas KE, Sapone A, Fasano A, Vogel SN (2006) Gliadin stimulation of murine macrophage inflammatory gene expression and intestinal permeability are MyD88-dependent: role of the innate immune response in Celiac disease. J Immunol 176: 2512-2521.

35. DeMelo EN, McDonald C, Saibil F, Marcon MA, Mahmud FH (2015) Celiac Disease and Type 1 Diabetes in Adults: Is This a High-Risk Group for Screening? Can J Diabetes 39: 513-519.

36. Arbuckle MR, McClain MT, Rubertone MV, Scofield RH, Dennis GJ, et al. (2003) Development of autoantibodies before the clinical onset of systemic lupus erythematosus. N Engl J Med 349: 1526-1533.

37. Toftedal P, Nielsen C, Madsen JT, Titlestad K, Husby S, et al. (2010) Positive predictive value of serological diagnostic measures in celiac disease. Clin Chem Lab Med 48: 685-691.

38. Burgin-Wolff A, Mauro B, Faruk H (2013) Intestinal biopsy is not always required to diagnose celiac disease: a retrospective analysis of combined antibody tests. BMC Gastroenterol 13: 19.
39. Zanini B, Magni A, Caselani F, Lanzarotto F, Carabellese N, et al. (2012) High tissue-transglutaminase antibody level predicts small intestinal villous atrophy in adult patients at high risk of celiac disease. Dig Liver Dis 44: $280-285$

40. Hill ID, Dirks MH, Liptak GS, Colletti RB, Fasano A, et al. (2005) Guideline for the diagnosis and treatment of celiac disease in children: recommendations of the North American Society for Pediatric Gastroenterology, Hepatology and Nutrition. J Pediatr Gastroenterol Nutr 40: 1-19.

41. Husby S, Koletzko S, Korponay-Szabó IR, Mearin ML, Phillips A, et al. (2012) European Society for Pediatric Gastroenterology, Hepatology, and Nutrition guidelines for the diagnosis of coeliac disease. J Pediatr Gastroenterol Nutr 54: 136-160.

42. Cianferoni A (2016) Wheat allergy: diagnosis and management. J Asthma Allergy 9: 13-25.

43. Catassi C, Bai JJ, Bonaz B, Bouma G, Calabrò G, et al. (2013) Non-Celiac Gluten Sensitivity: The New Frontier of Gluten Related Disorders. Nutrients 5: 3839-3853.

44. Bahna SL (2002) Cow's milk allergy versus cow milk intolerance. Ann Allergy Asthma Immunol 89: 56-60.

45. Kumar V, Wijmenga C, Withoff S (2012) From genome-wide association studies to disease mechanisms: celiac disease as a model for autoimmune diseases. Semin Immunopathol 34: 567-580.

46. Vojdani A, Perlmutter D (2013) Differentiation between Celiac Disease, Nonceliac Gluten Sensitivity, and Their Overlapping with Crohn's Disease: A Case Series. Case Reports Immunol 2013: 248482.

47. Choung RS, Marietta EV, Van Dyke CT, Brantner TL, Rajasekaran J, et al. (2016) Determination of B-Cell Epitopes in Patients with Celiac Disease: Peptide Microarrays. PLoS One 11: 0147777.

48. Sildorf SM, Fredheim S, Svensson J, Buschard K (2012) Remission without insulin therapy on gluten-free diet in a 6-year old boy with type 1 diabetes mellitus. BMJ Case Rep.

49. Guandalini S (2017) Pediatric Celiac Disease Clinical Presentation. Pediatrics: General Medicine, Medscape, USA.

50. Gomes RC, Cerqueira Maia J, Fernando Arrais R, André Nunes Jatobá C, Auxiliadora Carvalho Rocha M, et al. (2016) The celiac iceberg: from the clinical spectrum to serology and histopathology in children and adolescents with type 1 diabetes mellitus and Down syndrome. Scand J Gastroenterol 51: 178-185.

51. Barera G, Bonfanti R, Viscardi M, Bazzigaluppi E, Calori G, et al. (2002) Occurrence of celiac disease after onset of type 1 diabetes: a 6-year prospective longitudinal study. Pediatrics 109: 833-838.

52. Fasano A (2006) Systemic autoimmune disorders in celiac disease. Curr Opin Gastroenterol 22: 674-679.

53. Ehlers MR (2016) Immune Interventions to Preserve Beta Cell Function in Type 1 Diabetes. J Investig Med 64: 7-13.

54. Amador-Patarroyo MJ, Rodriguez-Rodriguez A, Montoya-Ortiz G (2012) How Does Age at Onset Influence the Outcome of Autoimmune Diseases? Autoimmune Dis 2012: 251730 .

55. Al-Hussaini A, Basheer A, Czaja AJ (2013) Liver failure unmasks celiac disease in a child. Ann Hepatol 12: 501-505.

56. Medline Plus (2018) Sclerosing cholangitis. Medical Encyclopedia, Medline Plus, U.S. Department of Health and Human Services National Institutes of Health, USA.

57. Majid N, Bernoussi Z, Mrabti H, Errihani H (2013) Celiac Disease, Enteropathy-Associated T-Cell Lymphoma, and Primary Sclerosing Cholangitis in One Patient: A Very Rare Association and Review of the Literature. Case Rep Oncol Med 2013: 838941. 
Citation: O'Bryan T (2018) Review of Three Pediatric Wheat-Related Disorder Cases with Disparate Clinical Manifestations. J Gastroenterol Hepatology Res 3: 020 .

58. Bjornsson E, Angulo P (2007) Cholangiocarcinoma in young individuals with and without primary sclerosing cholangitis. Am J Gastroenterol 102: 1677-1682.

59. Brandsaeter B, Friman S, Broome U, Isoniemi H, Olausson M, et al. (2003) Outcome following liver transplantation for primary sclerosing cholangitis in the Nordic countries. Scand J Gastroenterol 38: 1176-1183.

60. Feldstein AE, Perrault J, El-Youssif M, Lindor KD, Freese DK, et al. (2003) Primary sclerosing cholangitis in children: a long-term follow-up study. Hepatology 38: 210-217.

61. Kummen M, Schrumpf E, Boberg KM (2013) Liver abnormalities in bowel diseases. Best Pract Res Clin Gastroenterol 27: 531-542.

62. Duggan JM, Duggan AE (2005) Systematic review: the liver in coeliac disease. Aliment Pharmacol Ther 21: 515-518.

63. Rubio-Tapia A, Murray JA (2007) The liver in celiac disease. Hepatology 46: 1650-1658.

64. Vo HD, Xu J, Rabinowitz SS, Fisher SE, Schwarz SM (2014) The liver in pediatric gastrointestinal disease. J Pediatr Gastroenterol Nutr 59: 288299.

65. Hollon J, Puppa EL, Greenwald B, Goldberg E, Guerrerio A, et al. (2015) Effect of gliadin on permeability of intestinal biopsy explants from celiac disease patients and patients with non-celiac gluten sensitivity. Nutrients 7: $1565-1576$

66. Hagander B, Berg NO, Brandt L, Nordén A, Sjölund K, et al. (1977) Hepatic injury in adult coeliac disease. Lancet 2: 270-272.

67. Bardella MT, Fraquelli M, Quatrini M, Molteni N, Bianchi P et al. (1995) Prevalence of hypertransaminasemia in adult celiac patients and effect of gluten-free diet. Hepatology 22: 833-836.

68. Bonamico M, Pitzalis G, Culasso F, Vania A, Monti S, et al. (1986) [Hepatic damage in celiac disease in children]. Minerva Pediatr 38: 959-962.

69. Novacek G, Miehsler W, Wrba F, Ferenci P, Penner E, et al. (1999) Prevalence and clinical importance of hypertransaminasaemia in coeliac disease. Eur J Gastroenterol Hepatol 11: 283-288.

70. Jacobsen MB, Fausa O, Elgjo K, Schrumpf E (1990) Hepatic lesions in adult coeliac disease. Scand J Gastroenterol 25: 656-662.

71. Pollock DJ (1977) The liver in coeliac disease. Histopathology 1: 421-430.

72. Tozzoli R (2008) The diagnostic role of autoantibodies in the prediction of organ-specific autoimmune diseases. Clin Chem Lab Med 46: 577-587.

73. Wiesner RH (1994) Current concepts in primary sclerosing cholangitis. Mayo Clin Proc 69: 969-982.

74. Hay JE, Wiesner RH, Shorter RG, LaRusso NF, Baldus WP (1988) Primary sclerosing cholangitis and celiac disease. A novel association. Ann Intern Med 109: 713-717.

75. Ludvigsson JF, Elfström P, Broomé U, Ekbom A, Montgomery SM (2007) Celiac disease and risk of liver disease: a general population-based study. Clin Gastroenterol Hepatol 5: 63-69.

76. Casswall TH, Papadogiannakis N, Ghazi S, Németh A (2009) Severe liver damage associated with celiac disease: findings in six toddler-aged girls. Eur J Gastroenterol Hepatol 21: 452-459.
77. Schulze K, Weismuller TJ, Bubenheim M, Huebener P, Zenouzi R, et al. (2015) Criteria Used in Clinical Practice to Guide Immunosuppressive Treatment in Patients with Primary Sclerosing Cholangitis. PLoS One 10: 0140525 .

78. Tuncer S, Yeniad B, Peksayar G (2010) Regression of conjunctival tumor during dietary treatment of celiac disease. Indian J Ophthalmol 58: 433434.

79. Matijaca M, Pavelin S, Kaliterna DM, Bojić L, Matijaca A (2011) Pathogenic role of aquaporin antibodies in the development of neuromyelitis optica in a woman with celiac disease. Isr Med Assoc J 13: 182-184.

80. Hadjivassiliou M, Grünewald R, Sharrack B, Sanders D, Lobo A, et al. (2003) Gluten ataxia in perspective: epidemiology, genetic susceptibility and clinical characteristics. Brain 126: 685-691.

81. Laforenza U, Miceli E, Gastaldi G, Scaffino MF, Ventura U, et al. (2010) Solute transporters and aquaporins are impaired in celiac disease. Biol Cell 102: 457-467.

82. Melamed E, Levy M, Waters PJ, Sato DK, Bennett JL, et al. (2015) Update on biomarkers in neuromyelitis optica. Neurol Neuroimmunol Neuroinflamm 2: 134 .

83. Vojdani A, Mukherjee PS, Berookhim J, Kharrazian D (2015) Detection of Antibodies against Human and Plant Aquaporins in Patients with Multiple Sclerosis. Autoimmune Dis 2015: 905208.

84. Vojdani A (2015) Molecular mimicry as a mechanism for food immune reactivities and autoimmunity. Altern Ther Health Med 21: 34-45.

85. Jacob S, Zarei M, Kenton A, Allroggen H (2005) Gluten sensitivity and neuromyelitis optica: two case reports. J Neurol Neurosurg Psychiatry 76: 1028-1030.

86. Fasano A and Shea-Donohue T (2005) Mechanisms of disease: the role of intestinal barrier function in the pathogenesis of gastrointestinal autoimmune diseases. Nat Clin Pract Gastroenterol Hepatol 2: 416-422.

87. Maggiore G and Caprai S (2003) The liver in celiac disease. J Pediatr Gastroenterol Nutr 37: 117-119.

88. Pastore L, Campisi G, Compilato D, Lo Muzio L (2008) Orally based diagnosis of celiac disease: current perspectives. J Dent Res 87: 1100-1107.

89. Cenit MC, Olivares M, Codoñer-Franch P, Sanz Y, et al. (2015) Intestinal Microbiota and Celiac Disease: Cause, Consequence or Co-Evolution? Nutrients 7: 6900-6923.

90. Lerner A, Matthias T (2015) Possible association between celiac disease and bacterial transglutaminase in food processing: a hypothesis. Nutr Rev 73: 544-552.

91. Wacklin P, Laurikka P, Lindfors K, Collin P, Salmi T, et al. (2014) Altered duodenal microbiota composition in celiac disease patients suffering from persistent symptoms on a long-term gluten-free diet. Am J Gastroenterol 109: 1933-1941.

92. Peters U, Askling J, Gridley G, Ekbom A, Linet M (2003) Causes of death in patients with celiac disease in a population-based Swedish cohort. Arch Intern Med 163: 1566-1572.

93. Proal AD, Albert PJ, Marshall TG (2013) The human microbiome and autoimmunity. Curr Opin Rheumatol 25: 234-240. 